\title{
Aproximações sobre o conceito de território e sua relação com a universalidade das políticas sociais
}

Approaching the concept of territory and its relation to the universality of social policies

\section{Dirce Koga*}

\begin{abstract}
Resumo:
O presente texto é um diálogo sobre a perspectiva territorial nas políticas sociais brasileiras, tendo como cenário a lógica capitalista excludente em que se dá a luta cotidiana dos moradores pelo acesso à cidade e à cidadania. Em busca por algumas chaves de compreensão das dinâmicas presentes nos territórios de vivência dos que constituem os cidadãos de direito é que se propõe uma aproximação com o conceito de território e sua relação com a universalidade das políticas sociais e, ao mesmo tempo, com as rugosidades e densidades socioterritoriais.
\end{abstract}

Palavras-chave: Território. Políticas sociais. Cidadãos. Escala. Vivência.

\begin{abstract}
:
The text dialogue on territorial perspective on Brazilian social policies, against the backdrop of the exclusionary capitalist logic that causes the residents' daily struggle for access to the city and to citizenship. In search of some key understanding of the dynamics present in the territory of living of those who are citizens of law is that it proposes an approach to the concept of territory and its relation to the universality of social policies and at the same time, with roughness and socio-territorial densities.
\end{abstract}

Keywords: Territory. Social policies. Citizens. Scale. Experience.

\section{Introdução}

Em tempos de políticas sociais pautadas, cada vez mais, pela retórica e por referências, unilateralmente, voltadas para a pobreza como sinônimo renda precária ou

\footnotetext{
* Assistente Social, doutora em Serviço Social, professora titular do Programa de Mestrado em Políticas Sociais da Universidade Cruzeiro do Sul (São Paulo - SP). O presente texto é fruto de reflexões, sob o mesmo título do artigo, debatidas no I Seminário Nacional - Gestão de Políticas Sociais e Território - no âmbito do Projeto Procad Universidade Estadual de Londrina - PR - no dia 02/04/2013. dirce.koga@uol.com.br
} 
ausência da mesma, fazer um deslocamento de análise para a perspectiva territorial é um desafio tanto no âmbito conceitual como metodológico. Mais do que isso, em se tratando de políticas sociais no contexto brasileiro, marcado por profundas desigualdades socioeconômicas, trata-se de vencer um paradigma societário pautado sob a égide da pobreza como caricatura e, por isso, passível de ser personificada e identificada a partir de determinadas características individuais, que configurariam a pessoa do pobre.

$\mathrm{Na}$ perspectiva da socióloga Vera Telles, a pobreza é colocada, na sociedade brasileira, como algo naturalizado, que faz parte da paisagem urbana ${ }^{1}$, pois, paradoxalmente, foi incorporada e aceita no cotidiano dos cidadãos brasileiros, que se acostumaram com a mesma, em suas mais variadas expressões.

O presente texto busca dialogar sobre a necessária desnaturalização de determinadas tipologias utilizadas como sinônimos caricaturais e homogeneizantes de grupos populacionais específicos, que tomam como referência preferencial linhas de corte de renda, aliadas a outras características de perfil demográfico. Coloca-se em questão o risco de um reducionismo nessa tendência atual de estabelecimento de critérios, adotados por diferentes programas sociais brasileiros, calcados, exclusivamente, em características de pessoas e/ou famílias, desconsiderando a complexidade dos contextos em que estas vivem.

Tratar desses contextos significa dar um passo além da identificação individual e/ou familiar, no sentido de reconhecer as condições objetivas dos territórios em que vivem as populações sobre as quais se referem um cadastro, um programa ou um serviço prestado, no âmbito das políticas sociais. Condições objetivas sob o ponto de vista da acessibilidade aos direitos de cidadania (incluindo os direitos à urbanidade), que envolvem não somente seus aspectos formais, mas também e, principalmente, as diferentes informalidades, constituem fator determinante nas estratégias de sobrevivência da sociedade de mercado. Justamente por se localizarem no terreno da informalidade, as informações sobre as

\footnotetext{
1 Vera Telles, em seu trabalho intitulado "Pobreza e Cidadania" (2001), traz para o debate os conceitos de pobreza e cidadania como figurações da questão social no Brasil moderno, traçando um percurso socio-histórico de análise sobre a construção desse binômio, em que a pobreza é transformada em paisagem, parte da natureza da sociedade brasileira. "Como paisagem, essa pobreza pode provocar a compaixão, mas não a indignação moral diante de uma regra de justiça que tenha sido violada. Transformada em paisagem, a pobreza é trivializada e banalizada, dado com o qual se convive - com um certo desconforto, é verdade -, mas que não se interpela responsabilidades individuais e coletivas. " (TELLES, 2001, p. 32).
} 
estratégias de acessibilidade nem sempre são passíveis de serem capturadas pelas estatísticas oficiais, calcadas em características de pessoas e famílias, de forma desconectada das características e dinâmicas dos lugares onde vivem.

Em meio à divulgação dos resultados do Censo Demográfico 2010, o próprio IBGE Instituto Brasileiro de Geografia e Estatística -, revelava um estudo sobre grupos vulneráveis no Brasil. Nesse estudo, a proporcionalidade dos considerados vulneráveis, com base, somente, no quesito renda, foi sempre menor, em todas as regiões do país (média de 7,4\%), em relação aos considerados vulneráveis com base no quesito carência social $^{2}$, que atingiu uma média de $36 \%$ da população; os considerados vulneráveis pela combinação entre os quesitos renda e carência social chegaram a uma média de $22,4 \%$. Foram considerados não vulneráveis, nesse estudo, apenas 34,2\% da população brasileira.

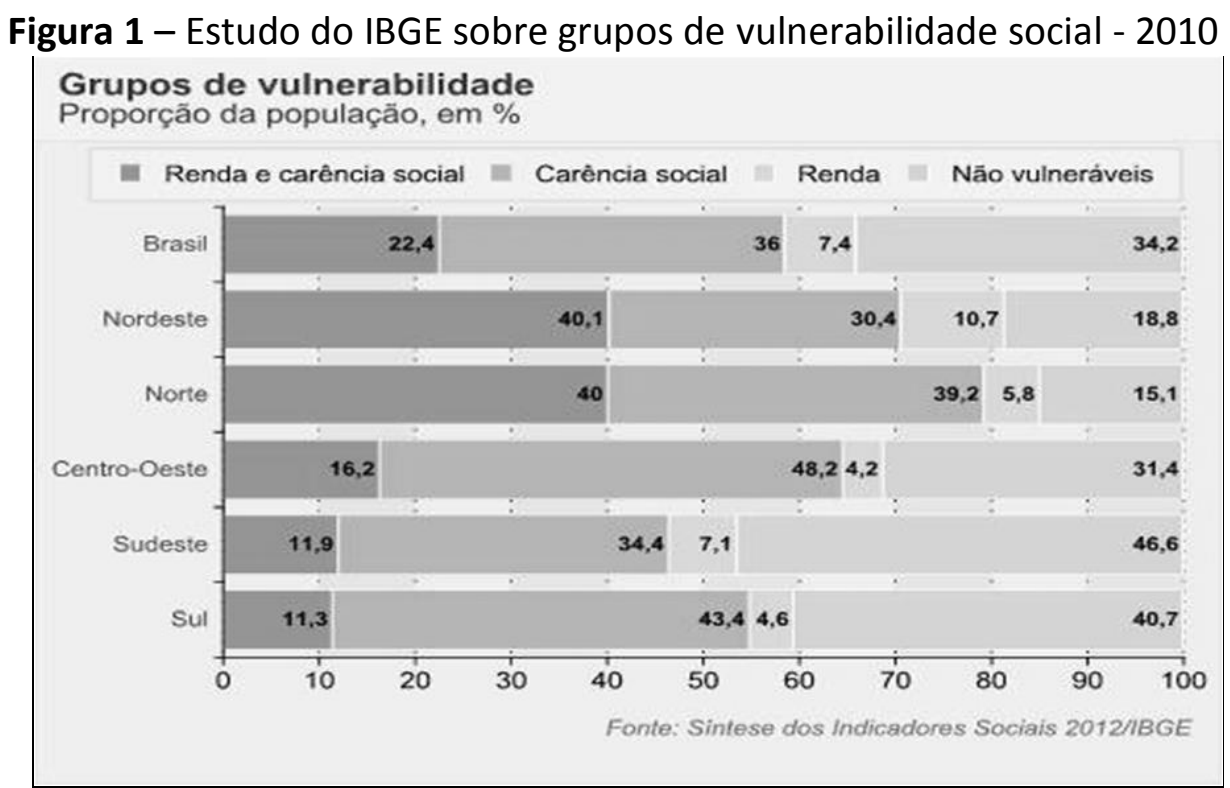

Fonte: Almeida (2012)

Conforme a reportagem, o "acesso a educação, seguridade social, a domicílio decente e a serviços básicos, além da renda, compõem o indicador de vulnerabilidade

\footnotetext{
2 Segundo a publicação do Jornal O Globo de 28/11/2012, "não é só renda que conta para se ter uma vida digna. Num entendimento mais amplo da pobreza, o IBGE uniu carências sociais às de renda e verificou que $22,4 \%$ da população podem ser considerados vulneráveis, de acordo com a Síntese de Indicadores Sociais 2012, divulgada nesta quarta-feira pelo instituto. Acesso a educação, seguridade social, a domicílio decente e a serviços básicos, além da renda, compõem o indicador de vulnerabilidade calculado pela primeira vez pelo IBGE. Se forem considerados os brasileiros que têm renda suficiente (ou seja, ganham mais do que R\$ 370 por mês), porém sofrem com algum tipo de carência social, chega a 36\% a parcela de brasileiros em situação precária. São 66 milhões na população de 184 milhões que vive em domicílio permanente. " (ALMEIDA, 2012).
} 
calculado pela primeira vez pelo IBGE. " (ALMEIDA, 2012). Desse modo, a impossibilidade de acesso aos direitos sociais básicos de cidadania, incluindo as condições dignas de habitar (domicílio decente e serviços básicos), impacta o cotidiano de $36 \%$ da população brasileira, além da renda.

Os outros indicadores de acesso emolduram um cenário que, embora tenham as cidades brasileiras como figuras centrais, não podem prescindir do elemento territorial como uma referência para a configuração de outros atributos a serem associados ao indicador de renda. Também não se trata, aqui, de considerar o território como um espaço, exclusivamente, físico ou administrativo, de divisão geográfica. O território embute as rugosidades da realidade, que, segundo Milton Santos (2002, p. 43), "não podem ser apenas encaradas como heranças físico-territoriais, mas também como heranças socioterritoriais ou sociogeográficas."

É pelo reconhecimento de tais rugosidades que se abrem algumas perspectivas para o debate sobre a aproximação do lugar do território nas políticas sociais brasileiras.

\section{Choque de escala - uma primeira aproximação com o território}

O modo de estruturação e atuação das políticas sociais brasileiras tem sido marcado por uma perspectiva segmentadora da realidade social, pois as necessidades e as demandas da sociedade são compartimentadas e selecionadas em públicos-alvo, seja pelas características etárias, pelas condições de renda ou pela vulnerabilidade e risco pessoal e social. No caso de algumas políticas, como a da assistência social, essa segmentação ainda tem prevalecido, apesar da Política Nacional de Assistência Social (2004) ter previsto a dimensão territorial como um de seus pilares de atuação, o que deflagrou as bases do SUAS - Sistema Único de Assistência Social.

Dessa forma, apesar dos avanços significativos e reconhecidos nos textos legais da política de assistência social, ainda permanece o legado da perspectiva homogeneizadora, que olha de forma, exclusivamente, segmentada as demandas e ofertas da política pública, desconectadas dos territórios onde ocorrem. Superar a perspectiva homogeneizadora dos segmentos constitui uma tarefa complexa em um campo de disputa política, pois, cotidianamente, são colocados, lado a lado, os paradigmas do direito e do favor, porque a 
proteção social, na sociedade brasileira, permanece como uma responsabilidade privada, circunscrita à esfera familiar e não pública.

Se, por um lado, se trata de um campo de disputa de ideários, por outro lado, se apresenta como um campo minado no processo de efetivação da própria assistência social como política pública. Nesse contexto, se, até o início do século XXI, a assistência social ainda carecia regulamentações, apesar da Constituição de 1988 e da Lei Orgânica de Assistência Social de 1993, hoje, ocorre uma proliferação de normatizações com o objetivo de estabelecer diretrizes nacionais para a gestão pública da política. Nesse processo, correse o risco de um afastamento da finalidade da política, que é o próprio cidadão, dada a quantidade, a velocidade e, por vezes, a verticalidade na construção do seu modus operandi, pois a tarefa envolve 5.565 municípios, de diferentes e desiguais escalas, que experimentam a efetivação de um campo comum de conceitos, significados e práticas.

Esse contexto em torno da política de assistência social pode sinalizar a necessidade de se construir algumas mediações, sejam elas sob o ponto de vista das responsabilidades estabelecidas entre os entes federados, sejam sob a perspectiva das próprias escalas e dinâmicas socioterritoriais a serem consideradas.

Nesse sentido, pode-se utilizar uma expressão criada por Antônio Miguel Monteiro, professor e pesquisador do INPE - Instituto de Pesquisas Espaciais, "o choque de escala", que se coloca como uma condição básica nos estudos territoriais, pois se trata de pensar sobre as perspectivas acionadas ao se realizar a aproximação com o território, enquanto categoria de análise, para se compreender determinadas condições socioeconômicas que se processam no cotidiano da vida das populações estudadas, a partir de seus locais de vivência.

Aproximar-se do território no âmbito das políticas sociais implica em um deslocamento de rota e de escala, que se afasta das médias e das homogeneidades, ao mesmo tempo em que busca articular elementos estruturantes às expressões manifestadas nas particularidades e singularidades dos lugares. Aqui se dá "o choque de escala", no momento em que se confrontam os grandes números produzidos pela escala mais abrangente da política social e os números miúdos das ocorrências e intercorrências da gestão local nos territórios de intervenção dessa mesma política social. 
O "choque de escala" produzido na aproximação com o território acaba por confrontar perspectivas distintas e discrepantes de uma realidade anteriormente vista como um conjunto homogêneo, similar a outros com características semelhantes. $\mathrm{O}$ confronto revela, por um lado, diferenças e discrepâncias em relação a outras realidades e, por outro, as próprias rugosidades socioterritoriais.

Um exercício de choque de escala pode ser observado ao se tomar como referência os indicadores para a definição de "moradia adequada", que são considerados para todo o país, pelo IBGE: densidade de até 2 moradores por dormitório; coleta de lixo direta ou indireta por serviço de limpeza; e abastecimento de água por rede geral e esgotamento sanitário por rede coletora ou fossa séptica. O mapa a seguir, que tem como base o Censo 2010, demonstra o quanto a "moradia adequada" ainda é uma realidade inexistente para boa parte das cidades brasileiras.

Figura 2 - Percentual de domicílios adequados por município - 2010

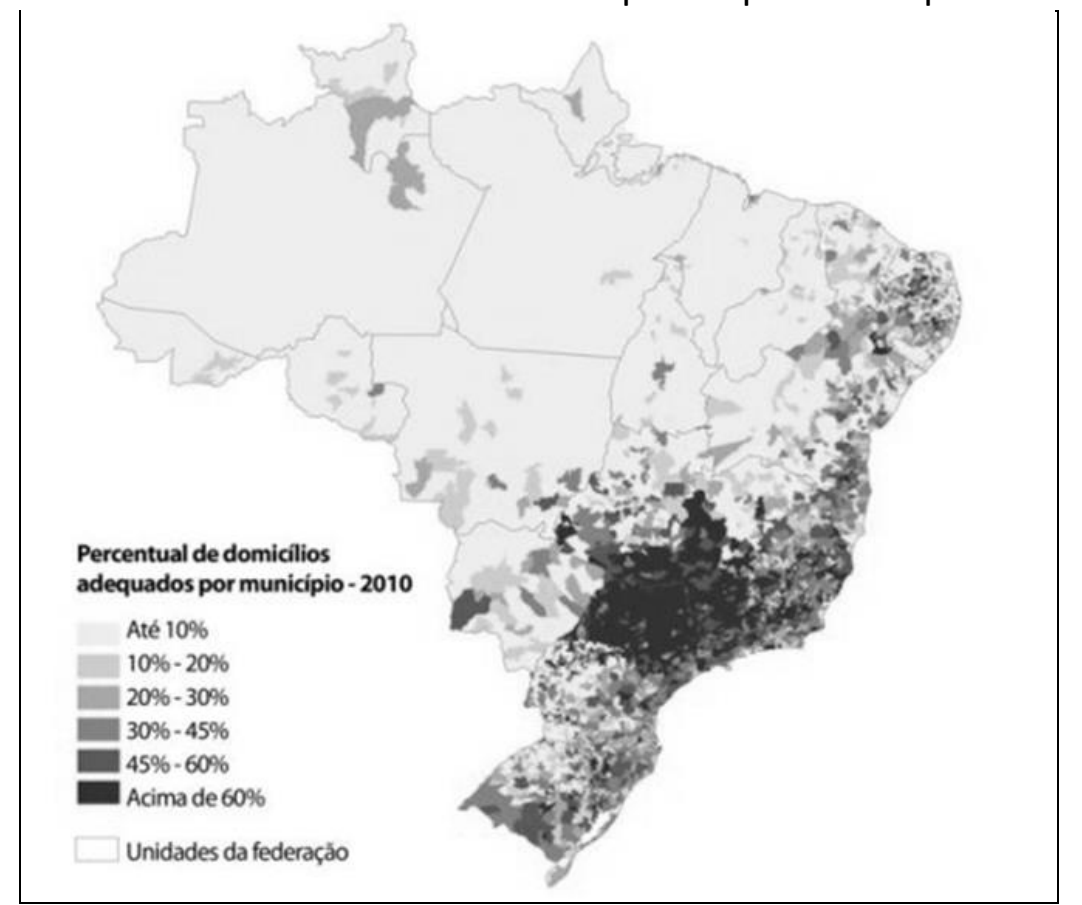

Fonte: Rolnik (2012).

Afirmar, simplesmente, que a "moradia adequada" ainda é uma realidade inexistente para "boa parte do país", de forma genérica, apresenta-se como uma compreensão distinta de quando se associa tal afirmação à perspectiva das cidades do país distribuídas cartograficamente. Descola-se de uma visão homogênea da presença/ausência 
de "moradia adequada" para uma visão de rugosidades de "moradia adequada", pois se observa que o fenômeno se concentra em determinados pontos do país e, praticamente, é nulo em outros. Esse deslocamento para uma perspectiva territorial provoca um "choque de escala". Nesse caso, a localização das cidades pelo imenso território brasileiro faz diferença.

Não se trata, aqui, de considerar, de forma ingênua e simples, que a cartografia, enquanto representação gráfica de espaços, seria suficiente para um deslocamento de perspectiva territorial. A cartografia, em si, não está em questão. Entretanto, seu potencial representativo, associado a uma perspectiva de análise que coloca a vertente territorial como um dos elementos constituintes da dinâmica da realidade, pode contribuir para um processo de "choque de escala".

Fica evidente, assim, que, nesse processo, há que se construir mediações entre as diferentes escalas produzidas e reproduzidas pelas políticas sociais. Se, por vezes, as grandes diretrizes das políticas públicas terminam por desconsiderar o movimento do real que se passa nas diferentes escalas do cotidiano vivido nas cidades brasileiras, também se faz necessário lembrar o quanto vêm sendo valorizadas, em outro extremo, as chamadas "experiências exitosas", confinadas, muitas vezes, em um localismo desconectado dos determinantes socioeconômicos dos quais fazem parte, bem como, da própria cidade.

Nesse contexto, o território se coloca para além do espaço físico, assim, não pode ser tomado como sinônimo de "espaço local" ou "comunitário", em sentido restrito. Segundo Vera Telles (2006), a noção de território não se confunde com "comunidade", expressão típica de um localismo desarticulado dos vasos comunicantes que se conectam à cidade e às diversas dimensões da vida.

É a partir dessa escala mais próxima do cotidiano de vivência que se buscará dialogar no próximo item desse artigo.

\section{A escala do território de vivência}

Um primeiro e fundamental cuidado se faz necessário ao se tratar da escala mais próxima do território, a que diz respeito ao cotidiano dos diferentes atores que circulam, residem e relacionam-se em determinados lugares: o reconhecimento de que o território 
expressa, ao mesmo tempo, produção e reprodução das relações socioeconômicas, políticas e culturais, presentes na sociedade que ele abriga.

Nessa perspectiva, a escala do território de vivência não pode ser confundida com um microterritório, uma simples miniatura de um território mais amplo, refletida localmente. O território de vivência aproxima-se, nesse caso, da dimensão do lugar denominada por Milton Santos:

O lugar é o quadro de uma referência pragmática ao mundo, do qual lhe vêm solicitações e ordens precisas de ações condicionadas, mas é também o teatro insubstituível das paixões humanas, responsáveis, através da ação comunicativa, pelas mais diversas manifestações da espontaneidade e da criatividade (SANTOS, 2002, p. 322).

Se o território de vivência possui peculiaridades, singularidades e dinâmicas próprias, acionadas e articuladas pelos diferentes atores sociais, sua configuração extrapola os limites da formalidade ou da institucionalidade estabelecida pelas políticas sociais, que, normalmente, regem sua atuação por meio de regras administrativas. Dentre estas regras, está a da divisão territorial, que delimita o pedaço do chão que pertence a cada morador, segundo o que a política de saúde ou de educação, por exemplo, determina como "área de abrangência".

A partir dessa institucionalidade, fica definido o acesso ou o não acesso aos programas e serviços existentes no território. Esse modo de operar aparenta garantir o acesso dos indivíduos, comprovadamente, residentes, porém, corre-se o risco de criar uma "camisa de força", que pode chegar ao ponto de estabelecer critérios mais excludentes do que includentes, ao negar o direito de cidadania. Nesse sentido, pode-se citar, por exemplo, o atendimento exclusivo a moradores de determinada área de abrangência de uma unidade de saúde, mesmo com a ocorrência de ociosidade, enquanto que, em outra área da cidade, seja comum uma longa lista de espera.

Outra situação que pode advir do uso, exclusivamente, político-administrativo do território, diz respeito às estratégias utilizadas pela população para "burlar" comprovantes de residência, recorrendo a amigos ou parentes para acessar um serviço, programa ou benefício. Ou seja, a rigidez ou o custo das formalidades termina por gerar estratégias informais para o acesso ao direito. 
Essas e outras diversas estratégias, na realidade, já compõem o complexo cotidiano de luta dos cidadãos residentes em territórios que, do ponto de vista da urbanidade, são considerados também informais, pela ausência de regularização fundiária. Nesse contexto, o drama está posto, pois, cada vez mais, os custos consequentes de uma regularização terminam por onerar e impactar a qualidade de vida dos cidadãos: as contas de água, energia elétrica e IPTU, somadas, podem chegar a superar a prestação da casa própria ou do aluguel.

Essa parece ser a lógica subjacente à atual configuração do mercado imobiliário, que David Harvey tem denominado como novo empreendedorismo urbano. Segundo ele,

[...] o novo empreendedorismo urbano se apoia na parceria público-privada, enfocando o investimento e desenvolvimento econômico, por meio da construção especulativa do lugar em vez da melhoria das condições num território específico, enquanto seu objetivo econômico imediato (ainda que não exclusivo) (HARVEY, 2006, p. 172).

Não se pode negar a regência orquestrada do mercado imobiliário especulativo, que se dá no cotidiano dos territórios das cidades brasileiras, em nome de uma urbanização, ou mesmo, de uma inclusão, pela realização do sonho da casa própria. É esse mercado que define onde se fará a cidade, um legado que vem sendo construído ao longo da história da urbanização brasileira. Nesse sentido, para Nakano (2008, p. 54):

\begin{abstract}
As cidades brasileiras expõem legados históricos que constituem dívidas socioterritoriais acumuladas durante séculos de urbanização segundo padrões desiguais do ponto de vista social, excludente do ponto de vista territorial e predatório do ponto de vista ambiental. Esse quadro de crise urbana aparece em diversos contextos regionais e socioambientais, desde as cidades da zona costeira até aquelas localizadas nas regiões do interior mais recôndito do país.
\end{abstract}

As afirmações de Harvey e Nakano evidenciam o cenário de conformação desse processo urbano-social excludente que marca as cidades brasileiras e coloca em cheque as políticas sociais, que, normalmente, não consideram esse chão sócio-histórico que subjaz no cotidiano de milhões de cidadãos brasileiros, mais moradores e menos cidadãos. Neste contexto, Ermínia Maricato ressalta que: 
“A terra é um nó na sociedade brasileira também nas cidades. A legislação é ineficaz quando contraria interesses de proprietários imobiliários ou quando o assunto são os direitos sociais." (MARICATO, 2011, p. 150).

Dessa forma, a lógica mercadológica parece perpassar outros espaços para além da política urbana. Mesmo a gestão social de programas, que elegem o território de residência ou a área de abrangência como mote de sua atuação, carrega marcas baseadas na matriz do "desenvolvimento econômico", quando coloca, como horizonte, a busca pela "autonomia", mediada por inúmeras ações de "capacitação profissional”, cujo ápice, hoje, se encontra na figura do "empreendedor".

A exemplo, as diretrizes do trabalho social, nos programas de urbanização de favelas HBB - Habitar Brasil e PAC - Programa de Aceleração do Crescimento, são baseadas em um tripé formado pelos seguintes eixos: 1) Educação Sanitária e Ambiental; 2) Participação e Organização Comunitária; e 3) Geração de Trabalho e Renda. Na visão de Raquel Paiva Gomes, estes eixos de ação, obrigatórios no trabalho social

[...] ainda reproduzem um conjunto de intervenções similares as das décadas de 1950 e 1960, fundamentado em uma matriz conceitual ortodoxa e conservadora, portanto, defasados frente aos desafios que emergem atualmente na operacionalização dos projetos integrados (GOMES, 2013, p. 26).

Percebe-se, para além da crítica de Gomes (2013), o quanto o tripé do trabalho social expressa uma concepção verticalizada das relações a serem estabelecidas entre os programas e os cidadãos de direito. Suas bases consideram os cidadãos como destituídos e despossuídos de toda e qualquer experiência de vivência individual e societária, como se fossem seres a serem domados para uma nova forma de convivência "harmoniosa e comunitária."

Importa ressaltar que permanece a perspectiva da "organização comunitária", que, salvo engano, está voltada mais para o estabelecimento de um sistema de regras condominiais a serem cumpridas em prol do "bem-estar" das famílias residentes no mesmo espaço habitacional: famílias sem história, desterritorializadas e desconectadas da cidade.

Desse modo, no âmbito da política de habitação, além de serem treinadas para se tornarem, ambientalmente, responsáveis e organizadas, as famílias são capacitadas para a 
geração de emprego e renda, o que acaba por evidenciar o viés empreendedor presente, cada vez mais, nos programas sociais de matriz governamental ou não governamental.

Cibele Rizek (2011), ao tomar como referência os programas de urbanização, tem utilizado a expressão "empresariamento da participação social" para o conjunto de ações, hoje, protagonizadas por empresas de consultoria, que são terceirizadas por governos (das três esferas), para realizar o trabalho social dos programas. Segundo a autora:

\begin{abstract}
O empresariamento da participação social, sob os novos rótulos de engenharia ou gerenciamento social, parece significar a ocupação empresarial de um reduto que classicamente pertenceu aos domínios da politização e da atuação dos grupos vinculados a uma perspectiva democratizante das dimensões habitacionais e urbanas. A participação ganha assim um novo estatuto de eficiência, gestão e controle, passando a fazer parte de uma espécie de reengenharia despolitizante da gestão da cidade e de suas populações (RIZEK, 2011, p. 354).
\end{abstract}

Esse processo de "empresariamento" em curso, combinado às lógicas de "condicionalidades" ou "contrapartidas", na gestão social de políticas públicas, conforma um cenário em que os cidadãos são vistos, cada vez mais, como consumidores e, cada vez menos, como sujeitos com direitos. Nessa tônica em que prevalece a entrega do serviço ou benefício como produto (ainda que sob algumas condicionalidades), o que importa é definir os critérios para identificar quem está mais apto a se adequar ao formato do produto a ser entregue.

\title{
Considerações finais
}

A escala da política pública é definida a partir de sua institucionalidade e de seus critérios e condicionalidades, mas os cidadãos são considerados sujeitos desterritorializados, pois seu território se limita a um comprovante de endereço fixo, sem vida e sem vivência. Tal escala não admite, em seu conteúdo, as "rugosidades" ou as "densidades" preconizadas por Milton Santos, conformando-se como um deserto de relações humanas nas práticas de gestão social, ora denominadas de trabalho social. Entretanto, para Milton Santos (2002, p. 319), “o intercambio efetivo entre pessoas é a matriz da densidade social." 
A ausência de "rugosidades" e "densidades" revela a ausência do território de vivência, da escala do cotidiano ainda pouco desvendada ou reconhecida pelas políticas públicas. Ainda se tem trabalhado sob a égide da cidade legal, que exclui e privilegia, ao mesmo tempo. A cidade ilegal ou real continua distante dos diagnósticos, planos e ações, conforme lembra Maricato (2011, p. 122): “Para a cidade ilegal não há planos, nem ordem. Aliás, ela não é conhecida em suas dimensões e características. Trata-se de um lugar fora das ideias."

É desse território de vivência que importa se aproximar para que possa ser estabelecido o lugar do território, de fato, nos pressupostos ideológicos das políticas sociais brasileiras.

\section{Referências}

ALMEIDA, C. Mais de um terço da população brasileira tem carências sociais e de ren da, diz IBGE. O Globo, Rio de Janeiro, 28 nov. 2012. Caderno Economia. Disponível em: <http://oglobo.globo.com/economia/mais-de-um-terco-da-populacao-brasileira-temcarencias-sociais-de-renda-diz-ibge-6856655>. Acesso em: 1 maio 2014.

GOMES, R. P. Avanços, impasses e desafios do trabalho social no âmbito dos programas federais de urbanização de favelas. Dissertação (Mestrado em Planejamento e Gestão do Território) - Fundação Universidade Federal do ABC, Santo André. 2013.

HARVEY, D. A produção capitalista do espaço. 2 ed. São Paulo: Annablume, 2006.

MARICATO, E. As ideias fora do lugar e o lugar fora das ideias. In: ARANTES, O.; VAINER, C.; MARICATO, E. A cidade do pensamento único: desmanchando consensos. 6 . ed. Petrópolis: Vozes, 2011. p. 121-192.

NAKANO, A. K. O planejamento e a gestão territorial no Brasil: entre o tecnocratismo e o direito à cidade. In: KOGA, D.; FÁVERO, E. T.; GANEV, E. Cidades e questões sociais. São Paulo: Terracota, 2008. p. 53-68.

RIZEK, C. S. Intervenções urbanas recentes na cidade de São Paulo: processos agentes, resultados. In: CABANES, R. et al.(Org.). Saídas de emergência. São Paulo: Boitempo, 2011. p. 339-358.

ROLNIK, R. Moradia adequada: quantas são e onde estão as moradias adequadas no Brasil? Blog da Raquel Rolnik [Internet]. São Paulo: USP, 8 jun. 2012. Disponível em: $<$ http://raquelrolnik.wordpress.com/tag/moradia-adequada, 2013>. Acesso em: 1 maio 2014.

SANTOS, Milton. A natureza do espaço. São Paulo: EDUSP, 2002. 
TELLES, V. S. Pobreza e cidadania. São Paulo: Ed. 34, 2001.

TELLES, V. S.; CABANES, R. (Org.). Nas tramas da cidade: trajetórias urbanas e seus territórios. São Paulo: Humanitas, 2006. 